University for Business and Technology in Kosovo

UBT Knowledge Center

Nov 2nd, 9:00 AM - Nov 3rd, 5:00 PM

\title{
Urban Heat Islands(UHI) Mitigation in Densely Urban city of Tirana, Albania: Materials, Energy, Comfort
}

Sokol Dervishi

EPOKA University, sdervishi@epoka.edu.al

Eltjona Lacaj

EPOKA University

Regina Vathi

EPOKA University

Follow this and additional works at: https://knowledgecenter.ubt-uni.net/conference

Part of the Architecture Commons

\section{Recommended Citation}

Dervishi, Sokol; Lacaj, Eltjona; and Vathi, Regina, "Urban Heat Islands(UHI) Mitigation in Densely Urban city of Tirana, Albania: Materials, Energy, Comfort" (2012). UBT International Conference. 5.

https://knowledgecenter.ubt-uni.net/conference/2012/all-events/5

This Event is brought to you for free and open access by the Publication and Journals at UBT Knowledge Center. It has been accepted for inclusion in UBT International Conference by an authorized administrator of UBT Knowledge Center. For more information, please contact knowledge.center@ubt-uni.net. 
Urban heat islands (UHI) mitigation in densely urban city of Tirana, Albania: Materials, energy, comfort

\author{
Sokol Dervishi*, Eltjona Lacaj, Regina Vathi \\ Department of Architecture, EPOKA University, \\ sdervishi@epoka.edu.al
}

\begin{abstract}
Urban Heat Island(UHI) is considered as one of the major problems in the 21 st century as a result of urbanization and industrialization of human civilization. The urban structures generate a large amount of heat from solar radiations and other sources (i.e. anthropogenic heat). This situation is even worse in cities with high density and large population and extensive economic activities, Tirana, a densely urbanized city, is seriously facing this problem.

In this context, the present paper is a review article aiming to present the actual state of the art on the development and the assessment of potential benefits (i.e. materials with high solar reflectance, urban vegetation) as UHI mitigation strategies for buildings and urban structures in Tirana, Albania. The analysis shows that the limited urban vegetation and inner-city neighborhoods structures are those ones in which the hazard potential of the UHI effect is shown to be the greatest. These neighborhoods have limited open space for tree planting and green area and therefore a lower maximum potential benefit. During the warming of the climate these neighborhoods face the greater consequences due to interactions between the UHI effect and global climate change. The results show that implementations of different strategies of urban heat island (UHI) mitigation can reduce negative impacts of hazards in cities, including overheating due to elevated temperatures, air pollution and associated public health effects. Such strategies also can lower the demand for air-conditioning-related energy production, reduce the effects of urban heat island and ultimately living in a better environment
\end{abstract}

Keywords: Urban heat island, Mitigation, Materials, Vegetation, Global warming

\title{
1. Introduction
}

The process of urbanization generates distinctive weather climate. Urban climate usually refers to Urban Heat Island phenomenon, which causes warmer temperatures in cities compared to suburban areas (Oke 1987, Voogt 2002, Crutzen 2004, Wickham et al. 2011). After 1905's, urban population is increased from 160 million to about 3 billion in just 100 years, and it is expected to increase up to 5 billion by 2025. Approximately 50-60\% of the world population lives in cities and town (Hardy et al., 2001). As a result of urbanization phenomenon urban geometry of the city is transformed. Cities compared to suburban areas, have larger surfaces of non-impermeable materials and are lack of vegetation. Crucial inputs as surface materials, meteorological data and urban geometry are required to study indoor and outdoor thermal comfort. 


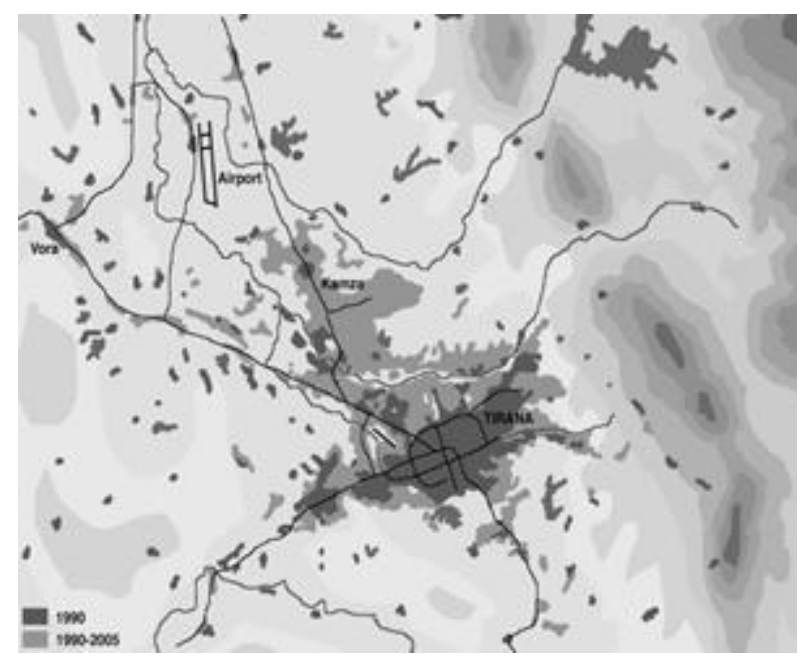

Figure 1 Urban expansion of Tirana from 1990-2005

The urban area of Tirana has faced dramatic changes on terms of population, as shown in figure 1, increasing it by 50\% from 1990 to 2001 (Vector Machine 2008, Nepravishta 2004). Population density has reached the levels of 14500 inhabitants $/ \mathrm{km}^{2}$ (Pojani 2011). Given this context this paper compares UHI impacts on urban and suburban areas.

Past researches have addressed this phenomenon several factors, mostly related to $\mathrm{H} / \mathrm{W}$ ratio and greenery surface (Toudert and Mayer 2006; Kiesel et al. 2012). Since UHI risked the urban comfort, there are completed significant researches on its impact to the environment (Montavez et al. 1999; Sarooni et al. 1999; Barrucand and Camilloni 2009; Giridharan and Kolokotroni 2009; Kruger et al. 2010; Chan 2011). Monteiro and Alucci used empirical measurements and survey to study the impacts of vegetation on reducing UHI impacts (Monteiro and Alucci 2007). Furthermore, Johansson and Emanuel argue the necessity for deeper canyons in urban design, trees and covered walkways, in order to minimize UHIs impacts (Johansson and Emmanuel 2007). In Tokyo, which is considered as a typical densely city, studies shows high UHI impacts due to higher energy consumption in residential buildings (Kikegawa et al. 2005).

Most of Urban Heat Islands impacts are spotlighted in hot humid climate, where its impacts are greater. Randomly there are carried out any studies on Mediterranean countries, with warm and humid climate. This study compares UHIs impacts on four different typologies of zones in Tirana:

I. Urbanized area (Tirana International Hotel, Center of Tirana)

II. Semi-Urbanized area (Kindergarten)

III. Closed typology of residential buildings (edifices enclosed in their perimeter)

IV. Non-Urbanized area (edifices surrounded by densely vegetation and soil environment)

Two main methods are applied to compute Urban Heat Islands intensity. The research performs a detailed site observation and surveys the inhabitants according to their indoor and outdoor thermal comfort. Furthermore, the study generates an evaluation between urban structure and meteorological conditions. 


\section{Study area}

The city of Tirana is located $41^{\circ} 19^{\prime} 48^{\prime \prime} \mathrm{N}, 19^{\circ} 49^{\prime} 12^{\prime \prime}$. The city is $512 \mathrm{~m}$ above Adriatic Sea level. Tirana's average altitude is $110 \mathrm{~m}$ and its highest point is $1828 \mathrm{~m}$. Hills on east side and a small valley on northwest surrounds the area. Throughout the city passes Lana River and are found four artificial lakes.

\subsection{Climate conditions}

Tirana is characterized by typical Mediterranean climate, with hot and dry summers, and cool and wet winters. Its average temperature is $15^{\circ} \mathrm{C}$. The highest temperature of $42{ }^{\circ} \mathrm{C}$ is reached on July, while the lowest one of $-10{ }^{\circ} \mathrm{C}$ is reached on January (as shown in figure 2). The annual rainfall is $1265 \mathrm{~mm}$. As shown in figure 3, the lowest precipitations occur during August and September.

\section{Temperatures in Tirana city}

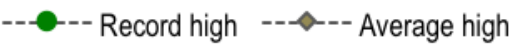

------- Average low ------ Record low

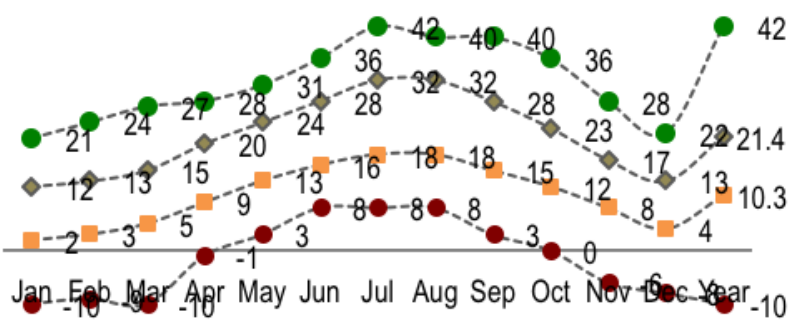

Figure 2 Temperatures in Tirana city

\section{Annual rainfall $(\mathrm{mm})$}
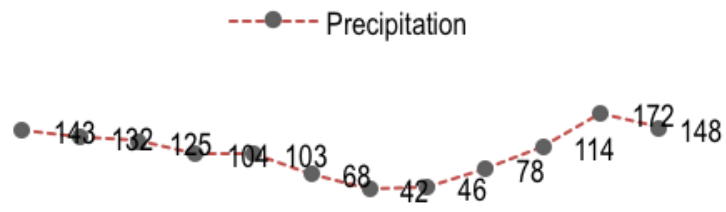

Jan Feb Mar Apr May Jun Jul Aug Sep Oct Nov Dec

Figure 3 Annual precipitations in Tirana city 


\subsection{Description of the area}

The four chosen zones to be analyzed have different characteristics and represent other similar zones in Tirana.

Zone 1 represents an urbanized area in the center of the city. It is characterized by large surfaces of dark and impermeable materials, high density of building and heavy traffic. The climatic conditions are characterized by high solar radiation and temperature, and low humidity especially during summer.

Zone 2 is considered as a semi-urbanized area, which is mostly occupied by residential buildings, few administrative buildings (hospitals, educational buildings, and municipal units) and plenty of uncultivated land. Synoptic conditions are characterized by higher solar radiation and temperature than zone 3 and lower than zone 1. The presence of greenery is higher than zone 1 and lower than zone 4 .

Zone 3 represents a closed typology of edifices where the presence of solar radiation and wind is low. Surrounding pavement is of asphalt and bituminous materials. Figure 4 shows a mapping of the four zones.

In zone 4, dense greenery and soil areas surround edifices. It represents a typical non-urbanized area, which has low density of buildings that do not exceed 2 floors storey. Referred to synoptic conditions, solar radiation is at the same levels as in zone 2 and 3. But it is characterized by a higher humidity and wind speed, compared to other selected zones.

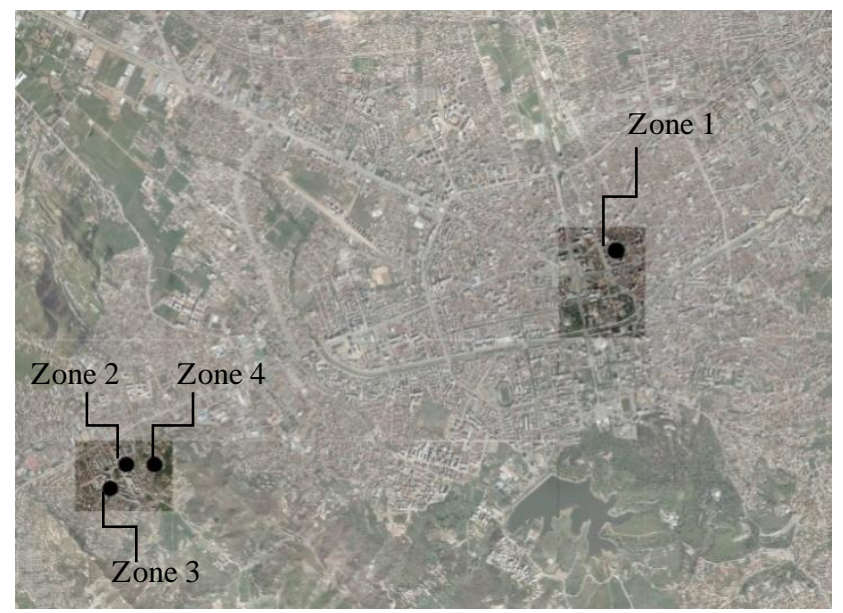

Figure 4 Location of selected zones

\section{Methodology}

\subsection{Meteorological data}

The following measurements, shown in figures 5-7 were performed during summer, from 1st June to 31st August 2012. The measurements are taken each day at the same time in each zone 1 $\mathrm{m}$ over the ground level. 


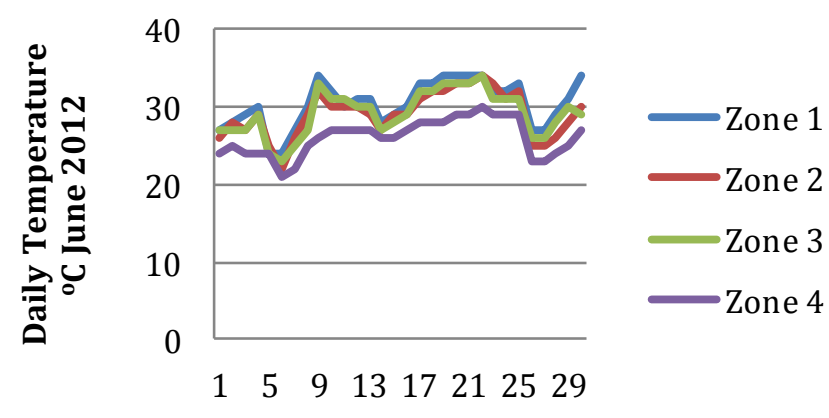

Figure 5 Daily air temperatures on June in selected zones

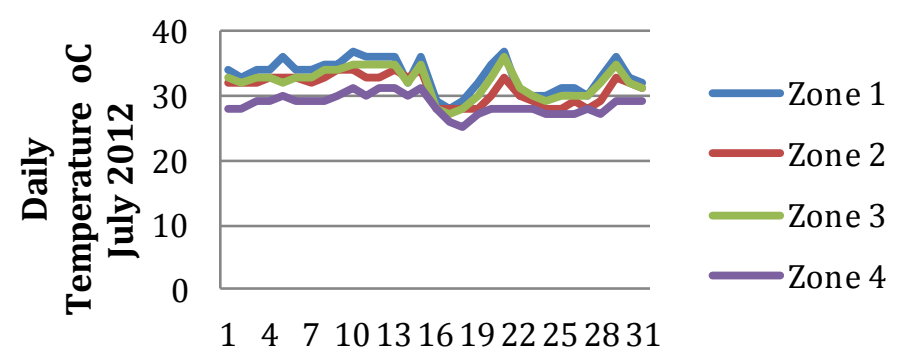

Figure 6 Daily air temperatures on July in selected zones

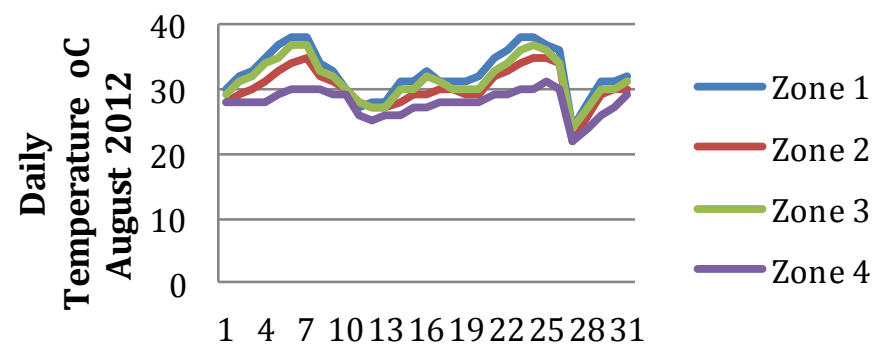

Figure 7 Daily air temperatures on August in selected zones

The data analysis aims to investigate UHI intensity and its impact on the outdoor comfort conditions. An initial elaboration is performed for the temperature measurements illustrated in figure 5, 6 and 7, each month respectively. The highest temperature values among all zones are recorded in the zone 1 (city center) and the lowest is recorded in the zone 4, surrounded by densely vegetation and soil environment.

The temperature measurements indicate an increase of temperature in urbanized areas, compared to non-urbanized areas. Between zone 1 and 4 it is recorded a maximum difference of 9oC (Figure 8). 


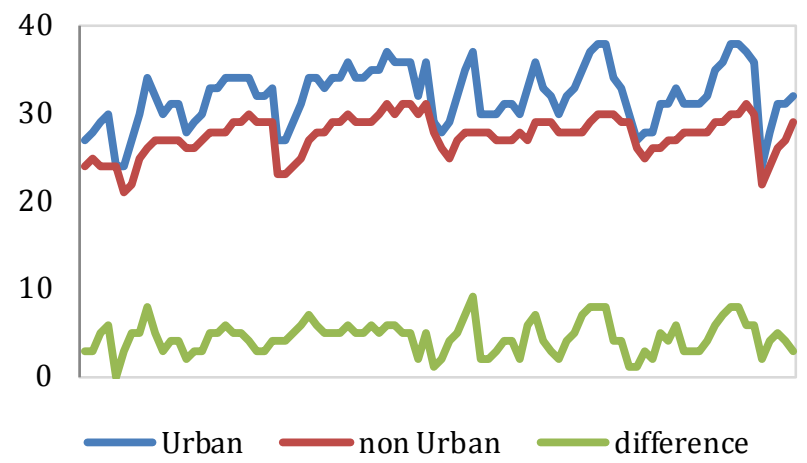

Figure 8 Temperature differences between zone 1 and 4

\subsection{Microclimate and urban geometry}

Urban canyons are strongly related with height-width ratio. The paper 'Effects of street design on outdoor thermal comfort' argues that $\mathrm{H} / \mathrm{W}$ ratio affects the amount of energy transported into urban canopy, surface temperature, potential irradiation of canyon facets and potential of wind flow at street level (Toudert, Mayer 2006 ).

-Situation 1:

Within the zone, the selected building is the highest one and the ratio $\mathrm{H} / \mathrm{W}$ is 1.15 . The building of $46 \mathrm{~m}$ height lies on the extension of the boulevard of $40 \mathrm{~m}$ (figure 9). Due to location during peak hours of the day is totally in shade and protected from direct solar radiation. This ration is valid only in the western orientation while in south where the building faces the Skanderbeg Square the ratio $\mathrm{H} / \mathrm{W}$ is lower and the area faces direct penetration of solar radiation. Consequently the surrounding environment gets overheated, due to paving materials (asphalt and bituminous products) and lack of being shaded.

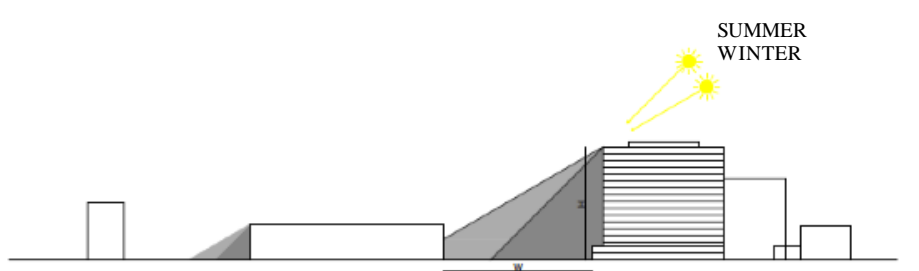

Figure $9 \mathrm{H} / \mathrm{W}$ of the International Hotel, Zone 1 -Situation 2: Kindergarten and its surroundings

The width between the kindergarten and surrounding edifices as shown in figure 10 is wide, approximately $31 \mathrm{~m}$, which does not allow the nearby buildings to shade south face of the kindergarten. $\mathrm{H} / \mathrm{W}$ ratio is 0.25 . Its location makes the kindergarten open to direct sun. The protection of indoor spaces from direct solar radiation is achieved by planting high trees with small canopies. The southern face is in shade. 


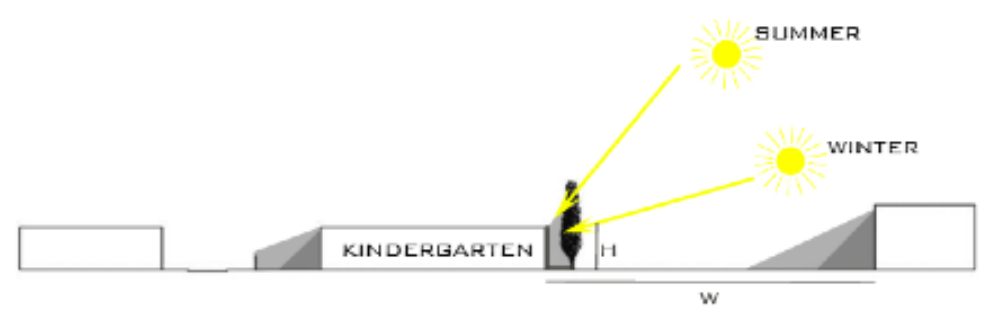

Figure $10 \mathrm{H} / \mathrm{W}$ ratio of kindergarten, Zone 2

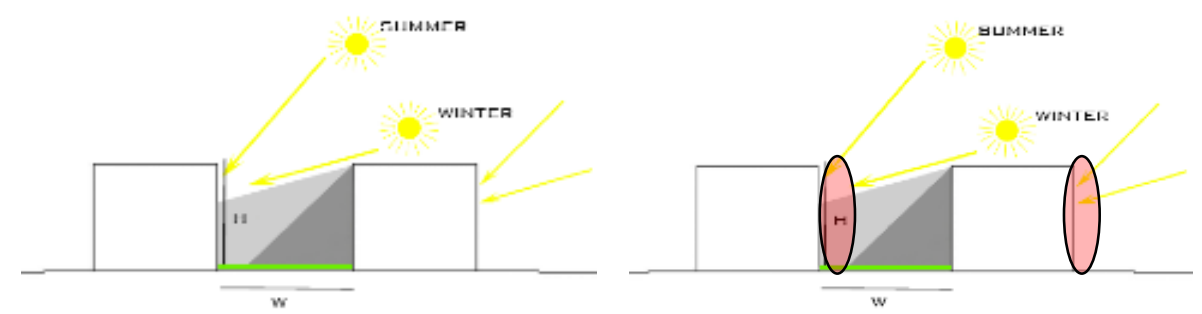

Figure $11 \mathrm{H} / \mathrm{W}$ ratio in enclosed urban area

Figure 11 explains how UHI impacts are present in an enclosed urban area. One of the south faces is fully in shade in winter, meanwhile in summer it is completely unprotected. The small distance between the buildings decelerates wind speed, which increase heat storage in between edifices. In summer both faces are unprotected from direct solar radiation, which increases the potential for heat storage increase.

-Situation 4: Non-urbanized area

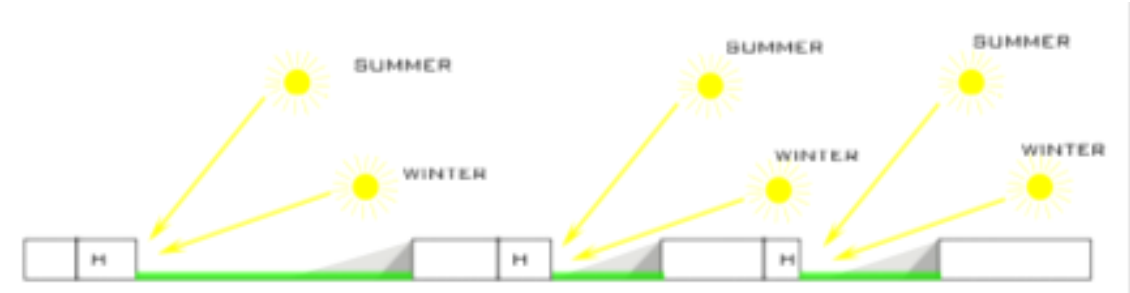

Figure $12 \mathrm{H} / \mathrm{W}$ ratio in non-urban area

Figure 12 shows the height-width ratio in semi-urban areas. This ratio varies approximately 0.16 . The smaller is the ratio, the greater is the gap between edifices. Consequently southern faces are affected by direct solar penetration, as there is no permanent protection. The presences of greenery increase humidity and accelerate wind speed.

\subsection{Survey}

The survey consists of an analysis of 75 habitants' behavior categorized into two groups: living in urban or non-urban environment. The average age of analyzed group is 31.6 where $62 \%$ are females and $38 \%$ males. $64 \%$ of the interviewers are permanent habitants in the zones, while 36 $\%$ are pedestrians. 


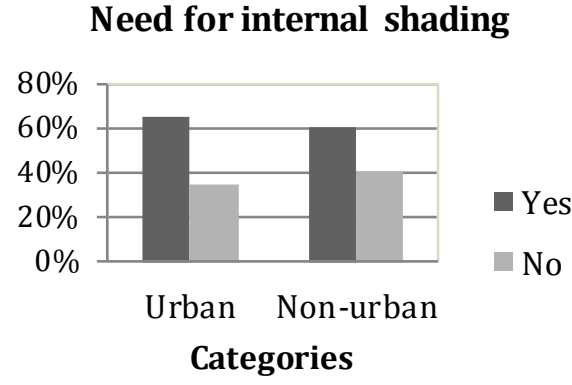

Figure 13 Need for internal shading of edifices

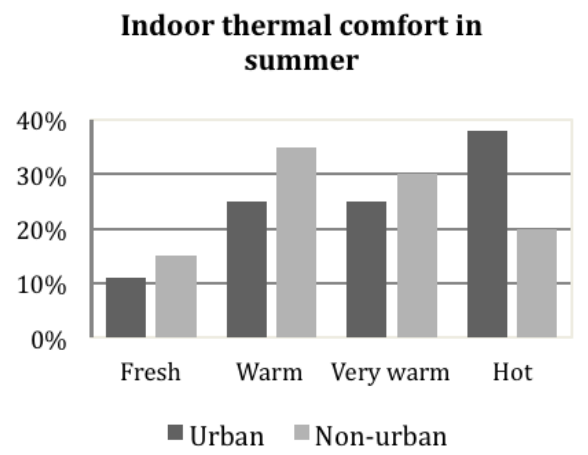

Figure 15 Need for internal shading of edifices

\section{Demand for air} conditioning

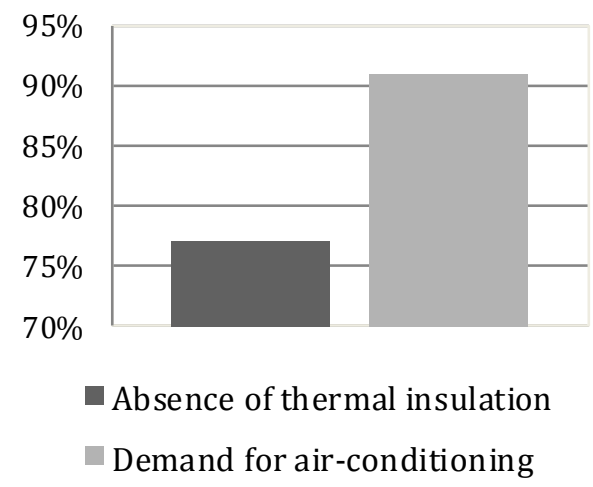

Figure 17 Demand for airconditioning

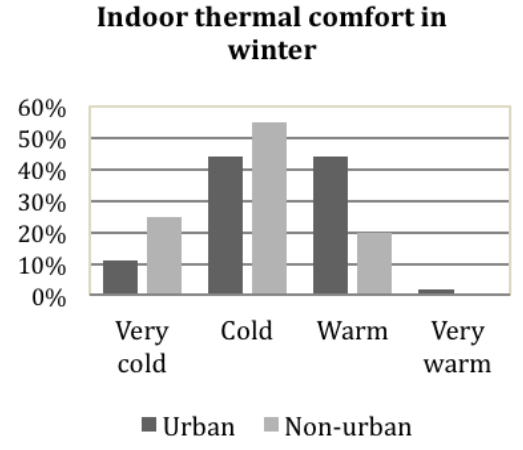

Figure 14 Indoor thermal comfort in winter

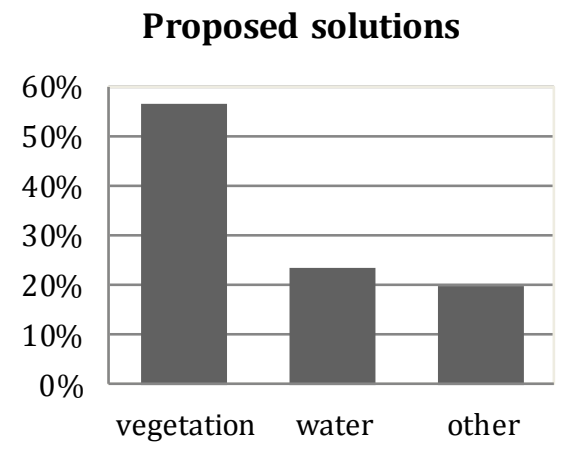

Figure 16 Proposed solutions 


\subsection{Surface materials and environmental impacts}

Materials are essential features of UHI phenomenon. The choice of materials is related with their reflectance and absorption capacity. The main surface materials used in the district are asphalt, concrete, brick, dark roof shingles, soil and vegetation. Positive and negative impacts of surface materials to surrounding environment are related to $\mathrm{CO}_{2}$, nitrous oxide and sulphur emission and reflectance properties of the materials. UHI impacts are more present in a polluted area, where levels of $\mathrm{CO}_{2}$ and aerosols in the air are higher (Akbari 2002).

Different materials have different impacts to environment. Brick releases about $54720 \mathrm{t} \mathrm{CO}_{2} / \mathrm{year}$ (Swiss Agency for Development and Cooperation SDC 2009). Concrete and asphalt are dominant materials in the district; therefore it is worthy to seriously take in consideration their impacts to the area. Concrete is used in two forms: 1) building materials (houses, edifices) 2) pavement. Meanwhile asphalt is mainly used in roads. Babor et al. argued that for every ton of concrete produced it is released in atmosphere $1.25 \mathrm{t}$ of CO2 (Babor et al. 2009). In the paper "Concrete and Climate Change" it is explained that per each square meter of a floor area we have about $550 \mathrm{~kg}$ of CO2 emission (Lemay and Lobo 2010).

As illustrated in figure 13 in Zone 2; $52 \%$ of the surrounding material is concrete, $25 \%$ asphalt and just $23 \%$ of the paving materials are greenery, including trees and grass.

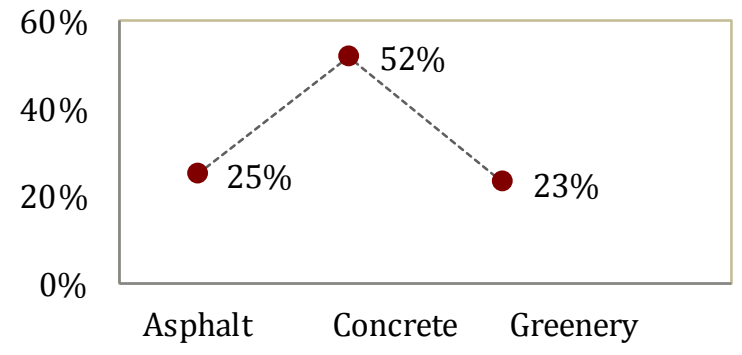

Figure 18 Material percentages in zone 2

\section{C02 emission $(\mathrm{t} / \mathrm{km})$}

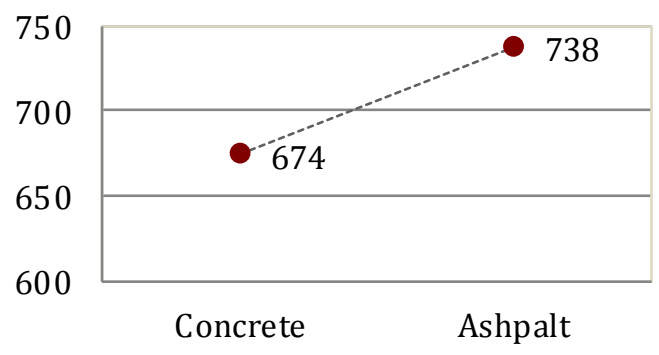

Figure $19 \mathrm{CO}_{2}$ emission: Concrete vs Asphalt

In the same research paper of Lemay and Loby, it came up that trucks driving in concrete surfaces rather than asphalt ones save about $50 \mathrm{t} \mathrm{CO} 2$ per $\mathrm{km}$. Figure 14 shows that concrete 
releases approximately $8 \%$ less $\mathrm{CO} 2$ than asphalt pavement. On the other hand concrete is brighter in color, which gives opportunity to save lighting energy. A concrete pavement saves $31 \%$ more energy than asphalt (Lemay and Lobo 2010).

Vegetations were shown to significantly modify air temperature at micro level; areas with $50 \%$ crown cover were cooler than those with no vegetation by $2.71{ }^{\circ} \mathrm{C}$ (Feyisa 2009). Due to the evapotranspiration process, vegetations absorb less heat from solar radiation, and cool down surface temperature. Consequently, in rural areas compared to urban ones, the temperatures are lower. Furthermore studies show that trees planted for summer shade, in western and eastern windows, reduce temperatures and cooling energy needs (Trees and Vegetation).

Figure 15 and 16 indicates the ration of greenery and urban spots for each zone respectfully. The greenery in uncultivated lands (zone 4) is characterized by low vegetations, which usually do not exceed $1 \mathrm{~m}$. Meanwhile greenery spots in urbanized regions are denser and have big tree canopy.

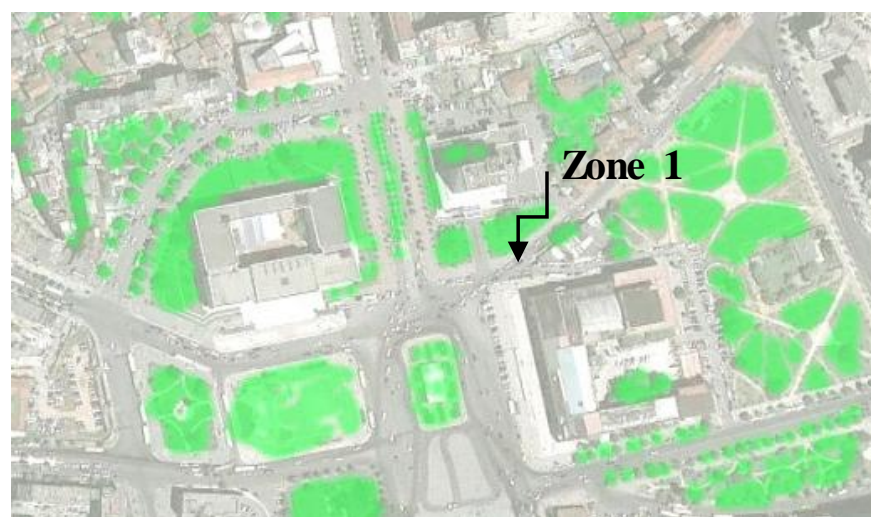

Figure 20 Greenery in Zone 1

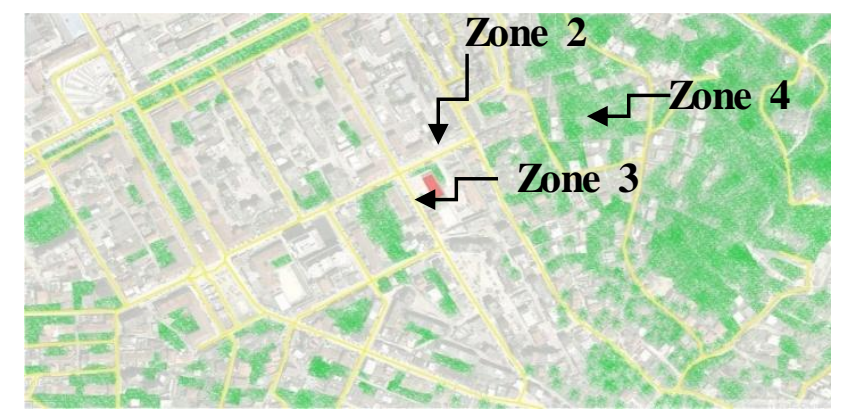

Figure 21 Greenery in Zone 2, 3 and 4

\section{Conclusion}

Urban Heat Island being the more documented phenomenon of climate change is usually expected to affect highly populated urban structures. The present study aimed to provide an additional quantitative analysis of the UHI in a Mediterranean City.

Analysis and experimental procedure taken in the four selected zones showed that UHI effects are seen more in the zones with a high urbanization, low vegetation, high percentage of concrete 
and asphalt material. The experiment was based also on an analysis of meteorological conditions of the city and temperature measurements on each zone at the same time for a period of three months during the summer. The results were clear that in the zones near the city center the temperatures were higher than in zones of periphery.

In order to have a more realistic analysis a survey was taken in each zone. And the result showed that also inhabitants were conscious about these changes and according to them some improvements can be made, as for example the increscent of vegetations and cooling out the road by usage of water fountains.

Some of the UHI mitigation strategies that can be applied in the zones can be (Mélissa Giguère, M.Env.):

\section{Greening measures}

Vegetation according to Nowak has different influences to:

Temperature reduction and other microclimate effects, reducing the temperature from $0.04^{\circ} \mathrm{C}$ to $0.2^{\circ} \mathrm{C}$ per percent canopy cover increase.

Decrease of air pollution, where according to Akbari, an average tree with a width of $31-46 \mathrm{~cm}$ (about $50 \mathrm{~m}^{2}$ in crown area) sequesters $\mathrm{CO}_{2}$ at a rate of $19 \mathrm{~kg} /$ year (Akbari 2002). Consequently the lower the air pollution less are UHI impacts.

\section{Urban intervention: Cool pavement}

Replacement of the present paving surface with materials of high albedo, lighter color and more ecological, is considered as a worthy solution against thermal distress.

The choice of materials is related with their reflectance and absorption capacity. Kiesel et al. argued that asphalt surfaces on rooftops can have an initial reflectance of 0.04 , while if it is covered with a smooth white coating, it will have a solar reflectance of 0.8 (Kiesel et al. 2012). Consequently the surface temperature will cool down. In the same research Kiesel pointed out that if these surfaces would be covered with vegetation the reduction of temperature will be greater. Some of the implementations could be:

- White aggregate

- White cement

- Two-lift paving (top surfaces with high albedo)

- Photocatalytic concrete

- Porous pavement and stone recharge beds for storm water retention (pervious concrete)

\section{Implementation of shading}

Recent ministerial statistics proof that energy effects on building. The survey resulted on $91 \%$ of interviewers need air-conditioning for cooling and heating. The largest is the energy consumption, the higher is $\mathrm{CO}_{2}$ release. Consequently the greater are UHI impacts. The challenge to reduce energy demand for heating and cooling can be reached by implementing external regulators as trees, which lowers the temperature, shade the building and block winds in winter (Nowak 2002).

Santos et al. recommends the use of solar shading devices in order to maintain a good indoor environment (Santos et al.).

\section{Cool roofs}


'Guidelines for selecting cool roofs' argue that cool roofing are eco-friendly approaches as far as they reduce air temperatures, peak electric power demand, power plant emissions and heat trapped in the atmosphere by reflecting more sunlight back into space (Urban B. and Roth K. 2010). The roofs in the surrounding environment usually are applied in dark colored shingles as dark red and brown. Instead of using such dark absorption materials, it is worthy to use high reflectance roofing, with brighter color.

Based in the same guideline, there can be used different cool roofing materials as: single ply membranes, metal roofs, built up roofs, modified bitumen sheet membrane and polyurethane foam (Urban B. and Roth K. 2010).

This study is important to understand the indoor and outdoor thermal challenges and to find out new applicable strategies to reduce environmental impacts. Prospective works will profound the studies on these 4 zones, based on a more detailed observation of surroundings' structure with specified technical tools and simulation software program.

\section{References}

Akbari H. 2002. Shade Trees Reduce Building Energy Use and CO2 emissions from Power Plants. Heat Island Group and Lawrence Berkeley National Laboratory. Berkley, USA. 1-8

Babor D, Plian D. and Judele L. 2009. Environmental impact of Concrete. BULETINUL INSTITUTULUI POLITEHNIC DIN IAŞI . 1-9

Barrucand M. and Camilloni I. Seasonal Analysis of the Urban Heat Island at Buenos Aires City. Accessed on April 1st 2012

BBC Weather Tirana. 2012.

Chan A.L.S. 2011. Developing a modified typical meteorological year weather file for Hong Kong taking into account the urban heat island effect. Building and Environment. Vol 46 p. 2434-2441.

Emmanuel R. and Johansson E.2006.Influence of urban morphology and sea breeze on hot humid microclimate: the case of Colombo, Sri Lanka. Climate Researh. Vol 30. p. 189-200.

Feyisa L. G. 2009. Role of Vegetation in Mitigating Urban Heat Island: The case study of Adama, Ethiopia. Univesity of Copenhagen. 1-2.

Giridharan R. and Kolokotroni M. 2009. Urban Heat Island characteristics in London during winter. Solar Energy. Vol 83. p.1668-1682.

Hardy, J.E., Mitlin, D., Satterthwaite, D., 2001. Environmental problems in an urbanizing world. Earthscan Publishers, London.

Kikegawa. Y; Genchi Y. Kondo Hiroaki and Hanaki.K.2005. Impacts of city-block-scale countermeasures against UHI phenomena upon a building's energy consumption for air conditioning. Applied Energy Vol.83 p. 649-668.

Lemay L. and Lobo C. 2010. Concrete and climate change: How does concrete stack up agains tother building materials? National Ready Mixed Concrete Association.p.1-8.

Maleki A.; Orehouning K. and Mahdavi A. 2012. Monitoring and Modeling of the Urban-Microclimate. ICAUD. 110. 
Mélissa Giguère, M.Env.2009, Literature Review of Urban Heat Island Mitigation Strategies, Direction de la santé environnementale et de la toxicology, Gouvernement du Québec, 13-43

Montavez J.P. Rodriguez A. and Jimenez I.J.2000. Study of the Urban Heat Island of Granada. The journal of Climatology. Vol.20 p.899-911.

Monteiro M. L.; Goncalves J. and Duarte D. Urban Design and Thermal Comfort:

Assessment of Open Spaces in Barra Funda; A Brownfield site in Sao Paulo, by Means of Site Measurements and Predictive Simulations. 1-8. Accessed on March 22nd 2012

Nowak J. D. 2002. The Effects of Urban Trees on Air Quality. USDA Forest Service. Syracuse, NY. 1-5

Pojani D. 2011. Trafik: Pushtimi I Tiranes nga Automjetet dhe sit e clirohemi. Epoka University Press. Tirana, Albania. p.15.

Santamouris, M., 2007. Heat island research in Europe, the state of the art. J. Adv. Build.

Energy Res., ABER.

Santos P. I.; Laustsen B. J and Svendsen S. Characterization and Performance Evaluation of Solar Shading Devices. 1-8. Accessed on May 2nd 2012

Sarooni H. Ben-Dor E. Bitan A. and Potchter.2000.Spatial distribution and microscale characteristics of the urban heat island in Tel-Aviv, Israel. Landscape and Urban Planning. Elsevier Vol.48 p.1-18.

Swiss Agency for Development and Cooperation SDC. 2009.RSA Brick Sector Facts and Emission Reduction Potential. Swiss Cooperation Office Southern Africa. 1-2

Tirana municipality 2006. "Tirana Outer Ring Road, Environmental and Social Impact Assessment Study". Bernard Engineers.

Toudert A. F. and Mayer H. 2006. Street Design and Thermal Comfort in Hot and Dry Climate. Accessed on March 21 st 2012

Trees and Vegetation. Reducing Urban Heat Islands: Compendium Strategies. Accessed on February 23rd 2012

Urban B. and Roth K. 2010. Guidelines for Selecting Cool Roofs. US Department of Energy.V.1.2

U.S. Department of Energy. 2010.Guidelines for selecting cool roofs. Energy Efficiency and Renewable Energy. V 1.2 p.1-23.

Vector Machine. 2008. Research project on the Geomatics Lab. Humboldt Universitat zu Berlin. Accessed on May 15th.

Voogt A. J. 2002. Urban Heat Island. Causes and Consequences of Global Environmental Change. John Wiley \& Sons. Ltd, Chichester. Vol 3 p. 660-666.

Wickham et al. 2001.Temperature land average using rural sites identified from MODIS classifications. p.1-14. Accessed on August 25th. 